\title{
Diminutives facilitate word segmentation in natural speech: Cross-linguistic evidence
}

\author{
VERA KEMPE \\ University of Stirling, Stirling, Scotland \\ Patricia J. BRoOks \\ College of Staten Island and the Graduate Center of City University of New York, Staten Island, New York \\ STEVEN GILlis \\ University of Antwerp, Antwerp, Belgium \\ AND \\ GRAHAM SAMSON \\ University of Stirling, Stirling, Scotland
}

\begin{abstract}
Final-syllable invariance is characteristic of diminutives (e.g., doggie), which are a pervasive feature of the child-directed speech registers of many languages. Invariance in word endings has been shown to facilitate word segmentation (Kempe, Brooks, \& Gillis, 2005) in an incidental-learning paradigm in which synthesized Dutch pseudonouns were used. To broaden the cross-linguistic evidence for this invariance effect and to increase its ecological validity, adult English speakers $(n=276)$ were exposed to naturally spoken Dutch or Russian pseudonouns presented in sentence contexts. A forced choice test was given to assess target recognition, with foils comprising unfamiliar syllable combinations in Experiments 1 and 2 and syllable combinations straddling word boundaries in Experiment 3. A control group $(n=210)$ received the recognition test with no prior exposure to targets. Recognition performance improved with increasing final-syllable rhyme invariance, with larger increases for the experimental group. This confirms that word ending invariance is a valid segmentation cue in artificial, as well as naturalistic, speech and that diminutives may aid segmentation in a number of languages.
\end{abstract}

Peter Jusczyk's seminal studies of the development of infant speech perception have spurred intense interest in exploring the learning processes that enable young children to discover the linguistic structures of their native language(s) (e.g., Jusczyk, 1997, 2002; Jusczyk \& Aslin, 1995; Jusczyk \& Hohne, 1997). One hypothesis, receiving renewed attention, is that general purpose associativelearning mechanisms play a crucial role in the acquisition of linguistic categories and structures (Gomez \& Gerken, 2000; Seidenberg \& MacDonald, 1999). At present, there is considerable evidence that infants and children are successful in tracking distributional patterns and regularities at a number of levels of linguistic analysis, including prosodic, phonological, morphological, and syntactic (e.g., Brooks \& Zizak, 2002; Gomez \& Gerken, 1999; Saffran, Aslin, \& Newport, 1996; Saffran \& Wilson, 2003). This work, which suggests that language acquisition involves the implicit learning of probabilistic regularities extracted from highly complex input, makes the particular distributional characteristics of the speech directed to children a topic of considerable interest, from both applied (e.g., Hoff, 2003; Huttenlocher, Vasilyeva, Cymerman, \&
Levine, 2002; Weizman \& Snow, 2001) and theoretical (e.g., Bates \& MacWhinney, 1987; Elman et al., 1996) perspectives. There now is a sizable body of research suggesting that child-directed speech might simplify, regularize, and highlight relevant linguistic structures and, thereby, might facilitate the language acquisition process (e.g., Golinkoff \& Alioto, 1995; Kuhl et al., 1997; Morgan \& Demuth, 1996; Tamis-LeMonda \& Bornstein, 2002; but see also Fernald \& McRoberts, 1996, for a note of caution). In this study, we focused on one feature of childdirected speech: the use of diminutives and its contribution to word segmentation.

One of the major challenges of language acquisition is to segment the incoming stream of continuous speech into discrete meaningful units. A large body of research has demonstrated that infants utilize many different sources of information as word segmentation cues; these include utterance boundaries (Brent \& Siskind, 2001), phonotactic regularities (e.g., Mattys \& Jusczyk, 2001b), transitional probabilities between phonemes or syllables (e.g., Saffran et al., 1996), and context- or position-sensitive allophony (e.g., Jusczyk, Hohne, \& Bauman, 1999; Mattys \& Jus-

V. Kempe, vk2@stir.ac.uk 
czyk, 2001a), as well as rhythmic and prosodic patterns (e.g., Jusczyk, Houston, \& Newsome, 1999; Morgan, 1996; Morgan \& Saffran, 1995). Child-directed speech has been shown to be much richer in word segmentation cues than is adult-directed speech, due to its exaggerated stress patterns, shorter utterances, and longer and more frequent pauses (Redford, Davis, \& Miikkulainen, 2004). Not surprisingly, computational word segmentation models have shown superior performance with child-directed speech input than with adult-directed speech input (Aslin, Woodward, LaMendola, \& Bever, 1996; Batchelder, 2002; Brent \& Cartwright, 1996; Christiansen, Allen, \& Seidenberg, 1998).

One feature that may facilitate word segmentation is the frequent occurrence of diminutives in child-directed speech. This idea was first expressed in Jusczyk (1997) and in Echols, Crowhurst, and Childers (1997). These researchers hypothesized that diminutives might benefit word segmentation by increasing the frequency of the dominant stress pattern. In English, diminutives (e.g., froggy, sockie, and Stevie) have a strong-weak metric stress pattern, which may serve to strengthen the bias for trochaic patterns typical for this language. Moreover, since diminutives are often derived by adding unstressed suffixes to word stems, it is possible that stress regularization is a general phenomenon in languages with frequent diminutives in child-directed speech. For example, Dutch diminutives comprise about $20 \%-30 \%$ of all childdirected noun tokens (Gillis, 1997), which increases the frequency of stressed-unstressed nouns in child-directed speech to $74 \%$ of multisyllabic word types (Taelman \& Gillis, 2000). In Spanish, many words with atypical stress assignment (e.g., mamá [Mom] and camión [truck], with stress on the second syllable) have a regular penultimate stress when diminutivized (e.g., mamita [little Mom] and camionito [little truck]). In previous work (Kempe, Brooks, \& Gillis, 2005), we tested this hypothesis by using an incidental-learning paradigm to present a stream of trochaic, iambic, and mixed Dutch pseudowords to speakers of English. The results confirmed that stressed syllables were, indeed, perceived as word onset cues.

However, regularized metric stress in diminutives is inevitably confounded with increased word ending invariance. By ending invariance, we mean the occurrence of the same or very similar phoneme combinations at the ends of words. Since languages contain limited numbers of diminutive suffixes, diminutivized words tend to have similar endings. For example, English diminutives, such as doggie, horsie, and birdie, all end in the same vowel, Russian diminutives end in $-i k,-k a$, or $-k o$, depending on noun gender, and Dutch diminutives end in $-t j e / t \mathrm{j} \partial /$ or one of its allomorphs. In Experiment 2 in Kempe et al. (2005), we investigated whether invariance in word endings introduced by diminutives facilitates word segmentation over and above the effects of regular trochaic (strong-weak) stress. We used Dutch materials because Dutch is a language with frequent and productive diminutive suffixation. Almost all Dutch concrete nouns can be diminutivized by adding the unstressed suffix -tje $/ \mathrm{tj} /$ or its variants (-etje /ot jə/, -pje /pjə/, -kje /kjə/, or -je /ja/) to simplex nouns, such as in stoel /stul/ [chair] -stoeltje/stult ja/[chairDIM]; glas/ylas/[glass]-glaasje /ylasja/ [glassDIM]; and raam /ram/ [window]-raampje /rampjə/ [windowDIM]. (Note that phonetically speaking, the $/ \mathrm{j} /$ segment assimilates with the preceding stop, yielding a voiced palatal resonant with a central conformational aspect of articulation. Or in other words, in fluent speech, the $/ \mathrm{j} /$ segment assimilates with the preceding obstruent, yielding a palatal approximant and turning the cluster into an affricate.) We manipulated the invariance in the consonant cluster and the vowel ending systematically to examine the independent contributions of consonant and vowel invariance found in Dutch diminutive affixes. The results showed that participants exhibited by far the best performance ( $70 \%$ correct) after listening to targets with maximal ending invariance-that is, targets modeled after Dutch diminutives. Furthermore, we found that performance improved most in conditions with invariant consonant clusters containing the affricate typical for Dutch diminutives.

This experiment demonstrated that ending invariance induced by diminutives improves word segmentation performance above and beyond the benefits from regular trochaic stress. However, this evidence was obtained from synthesized pseudonouns concatenated into a long artificial speech stream. Such input is very dissimilar to what children may receive as input in natural child-directed speech. Moreover, the presentation of Dutch pseudonouns limits the results to just one language. Thus, the generalizability of the finding that ending invariance in diminutives aids word segmentation is, so far, restricted to a condition of low ecological validity in just a single language. It is unclear whether ending invariance has the same status as a word boundary cue when embedded in natural speech in which multiple features may covary on different levels. Moreover, in highly inflected languages, where words tend to end in a limited set of inflections, the larger degree of naturally occurring ending invariance would complement the specific benefits associated with the diminutive suffix as a word boundary cue.

The aim of the present study was to extend the findings from Kempe et al. (2005) by providing cross-linguistic evidence for the beneficial effects of diminutives in a natural language context. Experiments $1 \mathrm{~A}$ and $1 \mathrm{~B}$ were attempts to replicate the diminutive benefit, using Dutch pseudowords embedded in natural Dutch speech. Experiment 2 extended the results to Russian, a typologically different language that is phonotactically more distant from English than is Dutch. Like Dutch, Russian is characterized by a pervasive use of diminutives in child-directed speech (Kempe, Brooks, Mironova, Pershukova, \& Fedorova, 2007; Kempe, Brooks, \& Pirott, 2001), with Russian mothers producing approximately $40 \%$ of all nouns in their diminutive form in their speech to young children. This extremely high frequency of diminutive use underscores the potential importance of diminutive suffixes as word boundary cues in this language. Obtaining cross-linguistic evidence from Russian, a Slavic language, will allow us to test the generalizability of the findings to other patterns of invariance besides the patterns typical for a typologically closer Ger- 
manic language such as Dutch, which may have been easily identifiable and preferred by speakers of English.

\section{EXPERIMENT 1A}

In this and the following experiments, we used an implicit-learning task to expose adult native speakers of English to pseudonouns embedded into the context of an unfamiliar natural language. We adopted the procedure of Saffran, Newport, Aslin, Tunick, and Barrueco (1997), which requires that participants engage in a distracting task, such as drawing, while being exposed to the speech stimuli. (Saffran et al. [1997] used a computerized drawing task, whereas we used a Spirograph game.) After exposure, the target pseudonouns are contrasted with foils in a forced choice recognition test to determine whether the participants were able to segment the targets out of the speech stream and recognize them as familiar units. In order to determine whether there are any a priori biases, the performance of the participants is compared with that of a no-exposure control group.

\section{Method}

Participants. One hundred sixty-eight native speakers of English (93 women and 75 men; mean age 21 years; range, 18-38 years) were recruited from undergraduate psychology courses at the University of Stirling and received course credit or $£ 4$ for their participation. Forty-two participants were pseudorandomly assigned to each of four between-subjects invariance conditions. Within each invariance condition, half of the participants were exposed to the speech stream before testing.

Materials. The materials consisted of six CCVC Dutch nonsense stems and six Dutch context sentences. The nonsense stems were combined with a second $\mathrm{C}(\mathrm{C}) \mathrm{V}$ syllable to create pseudonoun targets in which ending invariance was systematically manipulated (see Appendix A). The low-onset/low-rhyme-invariance condition resembled Dutch bisyllabic simplex nouns by combining the stems with six different consonant/vowel combinations, which were all dissimilar from each other. The low-onset/high-rhyme-invariance condition resembled the degree of rhyme invariance of Dutch diminutives by combining the same second-syllable consonant clusters with a schwa as the final vowel. The high-onset/low-rhymeinvariance condition resembled the degree of onset invariance of Dutch diminutive affixes by combining the onset of the three most frequent allomorphs of the Dutch diminutive-namely, glide $/ \mathrm{j} /$ and the obstruent glide clusters $/ \mathrm{tj} /$ and $/ \mathrm{pj} /$ - and the full vowels used in the low-onset/low-rhyme-invariance condition. Finally, the highonset/high-rhyme-invariance condition resembled the maximal ending invariance characteristic of Dutch diminutives, combining the stems with the three most frequent diminutive allomorphs: $-j e / j ə /$, -tje /tja/, and -pje/pjə/ (Booij, 1995).

To create foils for testing, the syllables of the six targets within each condition were recombined in such a way that the first syllables followed the second syllables. A full combination of the six targets and foils resulted in 72 target-foil combinations. All the targets and foils were recorded by a female native speaker of Dutch, using a trochaic stress pattern. The speaker was experienced in the recording of stimulus materials and practiced the production of the sentences until naturalness of embedding of the pseudonouns into the natural language context was achieved. It should be noted that the pseudonoun targets and foils were identical to those used in Kempe et al. (2005), with the exception that in the previous study, the stimuli were synthesized, as opposed to naturally recorded.

The 6 context sentences, each 12-14 syllables long, were selected from a children's book (targeting readers of about 10 years of age) in such a way that nouns appeared in various positions during the sentence (see Appendix A). For each sentence, one noun was replaced by one of the pseudonoun targets which was inserted into the sentence and recorded by the same native speaker. Within each condition, the six targets were combined with the 6 sentences, resulting in 36 unique target-sentence combinations. These 36 sentences were repeated 10 times and were combined randomly to create an approximately 18-min-long speech stream.

Procedure. In the exposure condition, the participants were given paper and colored pencils to create drawings, using a Spirograph game consisting of plastic templates of different shapes and sizes. After 5 min of practice, they were instructed to create a drawing, being as creative as possible. While drawing, the participants were exposed to the 18-min speech stream over headphones and were told that this was done to study the effect of sound on artistic creativity.

Next, the participants were seated in front of a Macintosh computer and, over headphones, were presented with the 72 target-foil test pairs in randomized order. For each pair, they were asked to decide which string sounded more familiar and to press one of two buttons on the keyboard corresponding to the first or the second string. If they could not decide, they were encouraged to guess. Error rates were recorded. After the test session, the participants were debriefed about the real purpose of the study by explaining that the goal was to test their ability to detect word boundaries in the speech stream without paying attention.

In the no-exposure control condition, the participants were presented with the 72 target-foil test pairs in randomized order and were asked to indicate, for each pair of strings, which string sounded more familiar, "like a sound they might have heard before," by pressing one of two buttons on the keyboard. All the participants were debriefed about the purpose of the experiment after completion of the forced choice test phase.

\section{Results and Discussion}

Table 1 presents the mean percentages of correct responses as a function of exposure condition, onset invariance, and rhyme invariance, as well as the results of onesample $t$ test against chance (50\%). Performance was at chance in all the no-exposure conditions, although there was a tendency for above-chance performance in the high-onset/ low-rhyme-invariance condition (e.g., target, knoochjie; foil, jieflijm $)(p=.06)$. In the exposure conditions, performance was above chance in all the conditions except the high-onset/ low-rhyme-invariance condition, where the one-sample $t$ test against chance fell short of significance $(p=.06)$.

Percentages of correct responses were submitted to a 2 (exposure condition) $\times 2$ (onset invariance) $\times 2$ (rhyme invariance) between-subjects ANOVA. There was a significant main effect of exposure condition $[F(1,160)=$ $\left.19.1, p<.01, \eta^{2}=.10\right]$, as well as a significant interaction between exposure and rhyme invariance $[F(1,160)=$ 5.6, $\left.p<.05, \eta^{2}=.03\right]$. Planned comparisons revealed significant differences between the exposure and the noexposure groups for the low-onset/low-rhyme-invariance condition $\left[F(1,40)=9.2, p<.01, \eta^{2}=.19\right]$; for the lowonset/high-rhyme-invariance condition $[F(1,40)=6.3$, $\left.p<.05, \eta^{2}=.14\right]$; and for the high-onset/high-rhymeinvariance condition $\left[F(1,40)=10.5, p<.01, \eta^{2}=.21\right]$, but not for the high-onset/low-rhyme invariance condition $(p=.96)$. Thus, the interaction was due to an in improvement in performance after exposure in both of the high-rhyme-invariance conditions, but only in one of the low-rhyme-invariance conditions. Recall that high rhyme invariance resulted in strings ending in a schwa. 
Table 1

Percentages Correct (\%C) as a Function of Final Syllable Onset and Rhyme Invariance (With Standard Deviations)

\begin{tabular}{|c|c|c|c|c|c|c|c|c|c|c|c|c|}
\hline \multirow{4}{*}{$\begin{array}{c}\text { Onset } \\
\text { Invariance }\end{array}$} & \multirow{4}{*}{$\begin{array}{l}\text { Rhyme } \\
\text { Invariance }\end{array}$} & \multirow[b]{4}{*}{ Condition } & \multicolumn{6}{|c|}{ Dutch } & \multirow{2}{*}{\multicolumn{4}{|c|}{ Russian }} \\
\hline & & & \multirow{2}{*}{\multicolumn{2}{|c|}{$\begin{array}{l}\text { Kempe, Brooks, } \\
\& \text { Gillis (2005) }\end{array}$}} & \multirow{2}{*}{\multicolumn{2}{|c|}{ Experiment $1 \mathrm{~A}$}} & \multirow{2}{*}{\multicolumn{2}{|c|}{ Experiment $1 \mathrm{~B}$}} & & & & \\
\hline & & & & & & & & & \multicolumn{2}{|c|}{ Experiment 2} & \multicolumn{2}{|c|}{ Experiment 3} \\
\hline & & & $\% \mathrm{C}$ & $S D$ & $\% \mathrm{C}$ & $S D$ & $\% \mathrm{C}$ & $S D$ & $\% \mathrm{C}$ & $S D$ & $\% \mathrm{C}$ & $S D$ \\
\hline \multirow[t]{4}{*}{ Low } & Low & No exposure & 49.1 & 8.7 & 49.3 & 6.4 & & & $54.0^{*}$ & 6.8 & & \\
\hline & & Exposure & $55.1^{*}$ & 8.0 & $55.9^{*}$ & 7.6 & $57.6^{*}$ & 10.8 & 51.8 & 9.0 & & \\
\hline & High & No exposure & 52.8 & 9.9 & 49.7 & 11.2 & & & 47.4 & 8.8 & $43.5^{*}$ & 8.8 \\
\hline & & Exposure & $57.4^{*}$ & 8.9 & $60.1^{*}$ & 15.2 & $62.2^{*}$ & 11.4 & $57.6^{*}$ & 9.1 & $54.2^{*}$ & 8.9 \\
\hline \multirow[t]{4}{*}{ High } & Low & No exposure & $55.2^{*}$ & 9.9 & 53.9 & 8.9 & & & $55.9^{*}$ & 9.6 & & \\
\hline & & Exposure & $64.3^{*}$ & 8.6 & 53.8 & 8.8 & $54.4^{*}$ & 8.2 & $57.3^{*}$ & 9.2 & & \\
\hline & High & No exposure & $57.1^{*}$ & 11.9 & 45.4 & 11.9 & & & $55.1^{*}$ & 10.8 & & \\
\hline & & Exposure & $70.1^{*}$ & 13.2 & $56.7^{*}$ & 10.6 & $58.7^{*}$ & 9.3 & $62.1^{*}$ & 12.1 & & \\
\hline
\end{tabular}

*Performance significantly different from chance (50\%).

Performance was above chance in three of the four exposure conditions and showed a strong tendency toward above-chance performance in the high-onset/low-rhyme condition. To see whether performance was different within the exposure conditions, we conducted a 2 (onset invariance) $\times 2$ (rhyme invariance) between-subjects ANOVA for the exposure conditions only. The effect of rhyme invariance fell short of significance $[F(1,80)=2.2$, $p=.14, \eta^{2}=.03$ ], suggesting a tendency toward superior performance for targets ending in schwas (58\% correct), as compared with targets ending in full consonants (55\% correct).

As in the Kempe et al. (2005) study, the results indicate that after exposure to the speech stream, the participants were generally better able to recognize the targets. For purposes of comparison, the data from that study are also shown in Table 1. In both experiments, the main effect of exposure may have been due to the application of the metrical segmentation strategy, which would have helped the participants to discover the trochaic targets by identifying stressed syllables as word onsets. Moreover, there is evidence that learners may represent stressed and unstressed syllables differently (Curtin, Mintz, \& Christiansen, 2005). If that is the case, stressed and unstressed versions of the same segmental unit would be perceived as different syllables and, thus, should be rejected as familiar in the test phase. However, the crucial finding is that there was an interaction with degree of invariance in the final syllable, which suggests that invariance information made an independent contribution to the identification of word endings. Specifically, we found an interaction between exposure and rhyme invariance that was due to improved performance in the two high-rhyme-invariance conditions. Thus, exposure to the speech stream increased the participants' sensitivity to final-syllable schwa endings as word ending cues, over and above any possible effects of trochaic stress. Interestingly, planned comparisons revealed that there also was improvement after exposure in the low-onset/low-rhyme-invariance condition, but not in the high-onset/low-rhyme-invariance condition. Note that performance in the latter condition (54\% correct) was highest in the no-exposure group, even though it fell short of significance when tested against chance. This sug- gests that there was a slight a priori advantage for some items with consonant clusters containing an affricate at the onset of the last syllable, a finding that was even more pronounced in Kempe et al. (2005). Presumably, since the test foils for this condition started with consonant clusters containing an affricate, this may have rendered them less word-like, thus resulting in a tendency to reject them as possible words, but only if they were not followed by schwas. This a priori bias may have overridden the effects of exposure to the invariance in the final syllable in this condition.

Despite the tendency to a priori reject foils starting with consonant clusters containing an affricate, the results confirm that when targets were embedded in a natural language context, listeners exposed to such speech were sensitive to patterns of final-syllable invariance and utilized them to segment words out of the phonotactically unfamiliar speech stream. However, in contrast to Kempe et al. (2005), we found that the benefit from final-syllable schwa endings was greater than the benefit from invariance in final-syllable onsets - that is, onsets containing an affricate. In Experiment 1A, sensitivity to schwa endings interacted with exposure condition, whereas it failed to do so in Kempe et al. (2005); that is, the exposure and the no-exposure groups showed a similar preference for wordfinal schwas. Experiment 1B tested whether this discrepancy may have arisen from the effect of the surrounding natural language context used in Experiment 1A, which contained few consonant clusters but many schwas and, most important, many schwa endings, as is typical for Dutch. To determine whether the distribution of schwas in the surrounding context affected the present results, we conducted a follow-up experiment in which a different set of context sentences was used.

\section{EXPERIMENT 1B}

\section{Method}

Participants. An additional 84 native speakers of English (53 women and 31 men; mean age, 21 years; range, 18-31 years) were recruited from the University of Stirling and received course credit or $£ 4$ for their participation. Twenty-one participants were pseudorandomly assigned to each of four invariance conditions with exposure to the speech stream. The performance of this additional 
participant group was compared with that of the no-exposure control group in Experiment 1A.

Materials. The target and foils were identical to those in Experiment $1 \mathrm{~A}$ but were combined with a different set of context sentences 21-25 syllables in length. The new sentences were created so as to minimize the number of word-final schwas. Since schwas are very frequent in Dutch, the new sentences contained many low-frequency words and, thus, resulted in natural sounding sentences with slightly strange, but not meaningless, semantics (see Appendix A). The new context sentences were recorded by the same native speaker of Dutch and were combined with the nonsense targets in the same way as in Experiment $1 \mathrm{~A}$.

Procedure. The procedure was identical to that in the exposure condition in Experiment 1A.

\section{Results and Discussion}

Table 1 presents the mean percentages of correct responses as a function of onset invariance and rhyme invariance and the results of one-sample $t$ tests against chance (50\%) for each condition. Performance was above chance in all the conditions.

Note that the change in context did not affect the actual targets and foils and did not alter the stimuli in the testing phase in any way. Thus, the no-exposure conditions in Experiment 1A still serve as valid controls for the new exposure conditions in Experiment 1B. We therefore combined the percentages of correct responses in the exposure conditions in Experiment 1B with the data from the no-exposure control conditions in Experiment 1A and submitted these to a 2 (exposure condition) $\times 2$ (onset invariance) $\times 2$ (rhyme invariance) between-subjects ANOVA. As in Experiment 1A, there was a significant main effect of exposure condition $[F(1,160)=31.9, p<$ $\left..01, \eta^{2}=.17\right]$, confirming that target recognition was superior in the exposure condition. The analysis also yielded a significant interaction between exposure and rhyme invariance $\left[F(1,160)=7.8, p<.05, \eta^{2}=.05\right]$. Planned comparisons revealed significant differences between the exposure and the no-exposure groups for the low-onset/ low-rhyme-invariance condition $[F(1,40)=9.1, p<.01$, $\left.\eta^{2}=.19\right]$; for the low-onset/high-rhyme-invariance condition $\left[F(1,40)=12.9, p<.01, \eta^{2}=.24\right]$; and for the highonset/high-rhyme-invariance condition $[F(1,40)=16.3$, $p<.01, \eta^{2}=.29$ ]; but not for the high-onset/low-rhymeinvariance condition $(p=.86)$. As in Experiment 1A, the interaction between exposure and rhyme invariance was due to an effect of exposure in both of the high-rhymeinvariance conditions, but only in one of the low-rhymeinvariance conditions.

In this experiment, performance was above chance in all four exposure conditions. To determine whether there were differences within the exposure conditions, we conducted a 2 (onset invariance) $\times 2$ (rhyme invariance) betweensubjects ANOVA for the exposure conditions only, which yielded a main effect of rhyme invariance $[F(1,80)=4.2$, $\left.p<.05, \eta^{2}=.05\right]$, due to superior performance for targets ending in schwas (60\% correct), as opposed to targets ending in various full vowels (56\% correct). The effect of onset invariance fell short of significance $[F(1,80)=2.3$, $p=.12, \eta^{2}=.03$ ], indicating that performance tended to be better in the low-onset conditions (overall, 60\% cor- rect) than in the high-onset conditions (overall, 57\% correct). This effect was due mainly to lower performance in the high-onset/low-rhyme-invariance condition, in which performance was only marginally above chance.

Despite the change in context, the results are very similar to those in Experiment 1A. As in Experiment 1A, the participants in Experiment 1B relied on final-syllable schwa endings to identify the targets. This result clearly disconfirmed the conjecture that the presence of many schwa endings in the surrounding context was the source of the participants' sensitivity to the schwa endings of the targets. Also, as in Experiment 1A, performance was worst in the high-onset/low-rhyme-condition, even though it did differ significantly from chance. This indicates that when exposed to strings such as knoochjie, the participants were not as good at identifying the affricate in the final syllable onset as a cue for an upcoming word boundary. This may suggest that in natural contexts, schwas are stronger word boundary cues than are consonant clusters containing an affricate, regardless of the frequency of schwas in the surrounding context. Another possibility is that the sound quality of affricates in synthesized speech, as presented in Kempe et al. (2005), was different from that in natural speech. That is, natural speech may have rendered affricates, or consonants in general, less salient when they were embedded in words. Crucially for the purposes of the study, however, we did find an improvement of word segmentation abilities after exposure to the speech stream, suggesting that learners can implicitly pick up invariance in the sound patterns of the language and utilize it as a cue for segmenting words.

To explore the cross-linguistic generalizability of these results, in Experiment 2, the same paradigm was used with Russian pseudonouns embedded in naturally spoken Russian sentences. We used Russian masculine nouns because their diminutive derivations do not end in vowels. Thus, we were able to examine whether sensitivity to rhyme invariance in final syllables would extend to a language that does not contain vowel (and more specifically, schwa) endings.

\section{EXPERIMENT 2}

\section{Method}

Participants. One hundred sixty-eight native speakers of English (106 women and 62 men; mean age, 21 years; range, 18-35 years) were recruited from the University of Stirling and received course credit or $£ 4$ for participation. Forty-two participants were pseudorandomly assigned to each of four invariance conditions. Within each invariance condition, half of the participants were exposed to the speech stream before testing.

Materials. The materials consisted of six CVC nonsense stems and six Russian context sentences. The CVC stems were combined with a second CVC syllable to create targets in which ending invariance was systematically manipulated (see Appendix B). The targets in the low-onset/low-rhyme-invariance condition resembled Russian masculine bisyllabic simplex nouns. In the low-onset/high-rhymeinvariance condition, the degree of rhyme invariance of Russian masculine diminutives was approximated by combining the secondsyllable onset with the Russian diminutive suffix $-i k$ /ik/ as coda. The high-onset/low-rhyme-invariance condition combined the finalsyllable codas characteristic of Russian masculine simplex nouns 
with the palatalized affricate onset $/ \mathrm{t} \mathrm{j} \int \mathrm{j} /$ characteristic of many Russian diminutives. Finally, in the high-onset/high-rhyme-invariance condition, the maximal ending invariance characteristic of Russian diminutives was approximated by combining all stems with the common diminutive suffix - chik $/ \mathrm{t} \mathrm{j} \mathrm{j} \mathrm{jik} /$. Foils were created in exactly the same manner as in Experiments 1A and 1B. All the targets and foils were recorded by a female native speaker of Russian, using a trochaic stress pattern.

The six context sentences, each 16-17 syllables long, were selected from a Russian children's book (targeting readers of about 10 years of age) in a way similar to that for the Dutch materials (see Appendix B). The six sentences were recoded by a female native speaker and were combined with the targets into 36 sentences per condition, as in Experiment 1A. The 36 sentences were repeated 10 times and were combined randomly to create an approximately 20-min speech stream.

Procedure. The procedure was the same as in Experiment 1A.

\section{Results and Discussion}

Table 1 presents the mean percentage of correct responses as a function of onset invariance and rhyme invariance, and the results of one-sample $t$ tests against chance $(50 \%)$ for each condition. Performance was above chance in all the conditions except the low-onset/highrhyme-invariance condition in the no-exposure group and the low-onset/low-rhyme-invariance condition in the exposure group.

Percentages of correct responses were submitted to a 2 (exposure condition) $\times 2$ (onset invariance) $\times 2$ (rhyme invariance) between-subjects ANOVA. There was a significant main effect of exposure condition $[F(1,160)=6.9$, $\left.p<.01, \eta^{2}=.04\right]$, indicating that performance improved after exposure to the speech stream. There was also a main effect of onset invariance $\left[F(1,160)=9.8, p<.01, \eta^{2}=\right.$ $.06]$, indicating that the participants generally performed better in the high-onset-invariance conditions. This suggests that there was an a priori bias so that the affricate $/ \mathrm{t} \mathrm{j} /$ in the final syllable supported target recognition. This is likely to have been due to the perceived unnaturalness of the foils starting with $/ \mathrm{t} \mathrm{j} \int \mathrm{j} /$, which may have facilitated foil rejection, leading to above-chance performance without exposure in the high-onset-invariance conditions. Note that this tendency is similar to what was observed in Kempe et al. (2005) and in Experiment 1A in this study.

Most important, the analysis yielded a significant interaction between exposure and rhyme invariance $\left[F(1,160)=8.2, p<.05, \eta^{2}=.05\right]$, showing that after exposure to the speech stream, the participants benefited most from final syllables ending in -ik. Note that this is the same interaction as that found in Experiments $1 \mathrm{~A}$ and $1 \mathrm{~B}$, which confirms sensitivity to final-syllable rhyme invariance across a range of languages and materials.

Planned comparisons revealed significant differences between exposure and no-exposure groups for the lowonset/high-rhyme-invariance condition $[F(1,40)=13.6$, $\left.p<.01, \eta^{2}=.25\right]$. For the high-onset/high-rhymeinvariance condition, the difference fell short of significance $\left[F(1,40)=2.8, p=.1, \eta^{2}=.07\right]$. There was no significant difference for the low-onset/low-rhymeinvariance condition and the high-onset/low-rhymeinvariance condition (all $p \mathrm{~s}>.3$ ). Note, however, that numerically, performance tended to be worse after ex- posure in the low-onset/low-rhyme-invariance condition. Although this finding should not be overinterpreted, given that this drop in performance was not significant, it may suggest that using metrical segmentation, which may aid word segmentation in the absence of invariance cues, may not work for Russian, where the strong-weak stress pattern is less apparent in the context than it is in Dutch. What is not quite clear is why, in this condition, the participants performed above chance when not exposed to the speech stream.

After exposure to the speech stream, performance was above chance in three out of four conditions. To determine whether there were differences within the exposure conditions, we conducted a 2 (onset invariance) $\times 2$ (rhyme invariance) between-subjects ANOVA for the exposure conditions only, which yielded a main effect of rhyme invariance $\left[F(1,80)=4.3, p<.05, \eta^{2}=.05\right]$, due to superior performance for targets ending in the suffix $-i k$ (overall, 60\% correct), as opposed to targets ending in other suffixes (overall, $55 \%$ correct). There was also an effect of onset invariance $\left[F(1,80)=4.8, p=.12, \eta^{2}=\right.$ $.06]$, indicating that performance was better in the highonset-invariance conditions (overall, 60\% correct) than in the low-onset conditions (overall, 55\% correct). Again, from the omnibus ANOVA, we know that rhyme invariance interacted with exposure, suggesting that the participants acquired sensitivity to this word boundary cue during exposure, whereas onset invariance had an a priori effect with and without exposure, suggesting that English speakers had a general tendency to reject strings with word-initial affricates as word candidates.

\section{EXPERIMENT 3}

In the previous two experiments, we investigated the role of ending invariance in natural language contexts for Dutch and Russian. The results indicated that participants performed better in segmenting words out of the speech stream when these words were invariant in their endings, particularly with respect to the final-syllable rhymes. However, the foils used to test the participants' ability to recognize these words were constructed following the principle used in Kempe et al. (2005), where target words were concatenated into an uninterrupted stream of speech without intervening materials. In that study and in Experiments $1 \mathrm{~A}$ and 1B, described above, the Dutch foils were constructed by recombining syllables of the targets so that the second syllables were followed by the first syllables. We used exactly the same foils in Experiments 1A and $1 \mathrm{~B}$ as those in Kempe et al. (2005) in order to allow a direct comparison of the results across studies. Whereas in Kempe et al. (2005) these foils resulted in syllable combinations that the participants encountered occasionally in the speech stream, in Experiments 1A and 1B of this study, the same principle of foil construction resulted in syllable combinations that were never encountered by the participants. The same principle was applied in the construction of the Russian foils in Experiment 2. One could argue that rejecting these unfamiliar syllable combinations might not have been indicative of the participants' abil- 
ity to identify word boundaries but merely reflected their familiarity with syllable combinations that co-occurred in the input. In order to make sure that the participants were indeed segmenting words out of the speech stream and distinguishing them from syllable combinations that straddled word boundaries, Experiment 3 contained a brief follow-up experiment to demonstrate, in principle, whether foils containing familiar syllable combinations that occasionally occurred in the speech stream would be rejected above chance after exposure. We decided to replicate one condition in Experiment 2-namely, the lowonset/high-rhyme-invariance condition-because in this condition, the participants demonstrated chance behavior in the no-exposure condition, indicating that there were no a priori preferences for the targets and the foils. We constructed a set of new foils by combining target syllables with the syllables preceding and following them in the natural language context.

\section{Method}

Participants. Forty-eight native speakers of English (27 women and 21 men; mean age, 21 years; range, 18-25 years) received course credit or $£ 4$ for participation. The participants were pseudorandomly assigned to either the exposure or the no-exposure condition.

Materials. The target items were identical to those in the lowonset/high-rhyme-invariance condition in Experiment 2. The foils were constructed by combining target syllables with syllables from the adjacent words in the natural sentence context. Specifically, we constructed two types of foils: (1) foils that combined the first target syllable with the preceding context syllable and (2) foils that combined the second target syllable with the following context syllable. This resulted in a total of 72 possible foils. Note that the syllables following the targets often contained a preposition and the first phoneme of the following noun, as in the sentence Predstav'te sebe, kak vygljadit takoj zhagbik na lune, where the syllable following the target, zhagbik, was nal, which contained the preposition $n a$ and the initial phoneme /1/ of the noun lune, resulting in the foil biknal. Since all the targets were trochees and four of the six syllables preceding the targets were stressed, this resulted in 24 foils with a stressed-stressed pattern. Similarly, the combination of the target trochees with the following syllables, five of which were unstressed, resulted in 30 strings with an unstressed-unstressed pattern. The remaining 18 foils followed a weak-strong pattern. Contrasting trochaic targets with iambic foils would be likely to result in an advantage for the targets just on account of their preferred stress pattern for native speakers of English. Therefore, these 18 iambic foils were left out of testing. In order to equate the number of stressed-stressed and unstressed-unstressed foils, 6 of the 30 unstressed-unstressed foils were also eliminated from the list. This resulted in a total of 48 foils, which were recorded as trochees. The change in stress pattern was unavoidable, since the production of unstressed-unstressed and stressed-stressed strings is highly unnatural and such strings would have a higher likelihood to be rejected as familiar and natural-sounding items by the participants. The six targets and 48 foils were combined into eight lists containing the six targets and 6 different foils in each list, following a Latin square design, so that the foils were matched for target syllable and original stress pattern as it occurred in the sentences. The eight foil lists are presented in Appendix C.

For each of the eight lists, the six targets and six foils were combined in the same way as in Experiments 1 and 2 and were presented in 72 target-foil pairs. Each list was presented to 3 participants in the no-exposure condition and to 3 participants in the exposure condition.

Procedure. The procedure was identical to those in Experiments 1 and 2 .

\section{Results and Discussion}

The far right column of Table 1 presents the mean percentages of correct responses in the exposure and noexposure conditions and the results of one-sample $t$ tests against chance $(50 \%)$ for each condition. Performance was systematically below chance in the no-exposure condition; that is, the participants showed a systematic a priori bias to prefer the foils as more familiar and natural sounding. It is not quite clear why the participants tended to prefer the foils in the no-exposure condition. Since we did not control for English phonotactic probabilities within the Russian pseudowords, it is possible that English phonotactic probability was higher for the foils than for the pseudonoun targets. As a result, the syllables taken from the natural Russian context may have sounded more word-like to native English speakers. Crucially, however, in the exposure condition, performance was above chance, indicating that the participants had learned to segment the targets out of the speech stream and could reliably distinguish them from combinations containing preceding and following syllables. The difference between the noexposure and the exposure conditions was significant $\left[F(1,46)=17.5, p<.001, \eta^{2}=.28\right]$.

This result confirms that the participants were, indeed, able to segment the targets out of the speech stream and to recognize them reliably, as compared with foils containing syllable combinations that straddled word boundaries. Despite the fact that some syllables in the foils contained segments of two Russian words (e.g., a preposition and a noun onset) and that the stress pattern had to be changed for the forced choice task, Experiment 3 provided converging evidence that ending invariance, particularly invariance in the final syllable rhymes as in the suffix $-i k$, typical for masculine Russian diminutives, can serve as a word boundary cue.

\section{GENERAL DISCUSSION}

A large body of research has shown that spoken language is rich in word segmentation cues, such as utterance boundaries (Brent \& Siskind, 2001), metrical stress regularities (Cutler, 1994; Cutler \& Norris, 1988), and context- or position-sensitive allomorphy (e.g., Jusczyk, Hohne, \& Bauman, 1999; Mattys \& Jusczyk, 2001a). In this study, we tested yet another word segmentation cue, invariance in word endings. The stimuli in the experiments reported here were modeled after Dutch and Russian diminutives because diminutives are a pervasive feature in child-directed speech. Diminutive morphemes may serve as word segmentation cues because they increase invariance of word endings. We systematically varied the invariance components found in Dutch and in Russian diminutive suffixes in an incidental-learning paradigm to examine whether adults are sensitive to these invariance components and, if so, which invariance components are the most useful segmentation cues.

The experiments reported here revealed a consistent pattern: When targets were recorded in natural speech and embedded in a natural language context, the participants unfamiliar with the phonotactics of the language 
became sensitive to the invariance in the final-syllable rhymes - specifically, the schwa in Dutch and the masculine diminutive suffix $-i k$ in Russian. This demonstrates that the invariance effect generalizes to another, typologically diverse language and is not just linked to specific features of Dutch diminutives. Ending invariance would seem to be a strong candidate for a cross-linguistically universal word segmentation cue.

Why should a frequently reoccurring phoneme or phoneme combination - specifically, a diminutive suffixindicate a word boundary? For learners exposed to a speech stream containing recurring phonemes or phoneme combinations, these invariant patterns will accrue familiarity simply due to their higher frequency. Thus, it is possible that strings containing these unstressed familiar syllables, when presented during test, are perceived as more familiar, perhaps even if the preceding syllables have never been encountered before. This, however, would indicate that syllables such as - -2 or $-i k$ are perceived as plausible word endings, thus taking on the function of a segmentation cue. Moreover, recall that in our materials, all the targets were recorded following a trochaic stress pattern. Thus, the increased salience and frequency of the segmental patterns of the second syllable was always preceded by stress on the first syllable. Listeners may have learned to associate metrical stress information with patterns of segmental invariance. Thus, we suggest that one segmentation cue, metrical stress, may aid in the identification of another segmentation cue, ending invariance. Further experiments will have to ascertain whether segmental invariance may serve as a word boundary cue in the absence of stress information.

This study confirmed that invariance in word endings facilitates word segmentation under more ecologically valid and natural conditions than the ones used in a previous study (Kempe et al., 2005). However, the present findings differed somewhat from the findings reported in Kempe et al. (2005), where the participants acquired sensitivity to final-syllable onsets-specifically, the affricates characteristic of Dutch diminutives. However, in that study, we used artificially synthesized stimuli concatenated into large meaningless streams of pseudonouns, whereas here we used naturally spoken targets embedded in meaningful natural sentences. The discrepancy between the results of that study and the results reported here demonstrates that effects obtained under artificial conditions may have limited applicability to ecologically more valid conditions. Note also that when targets were embedded into a natural language context, the participants needed considerably fewer instances of target exposure (60, as compared with 300 in Kempe et al., 2005) to extract the relevant invariance components. Obviously, in the present experiments, word segmentation was additionally facilitated by other segmentation cues normally present in natural speech (e.g., metrical stress or position-sensitive allomorphy). Future work is needed to ascertain adults' sensitivity to other segmentation cues, given limited exposure to an unfamiliar language.

In general, any type of ending invariance induced by a morphological change that applies to word endings could facilitate word segmentation. Thus, there is no reason to assume that similar effects could not be obtained from frequently occurring plural morphemes or inflectional endings on verbs. Moreover, in inflectionally rich languages, a number of morphemes may serve as invariant word boundary cues. For example, the case-marked endings of Russian diminutive masculine nouns such as -ika (gen. sing.), -iku (dat. sing.), -ike (loc. sing.), -iki (nom. pl.), or -ikam (dat. pl.) might serve as potential invariance cues, their informativeness depending on their frequency in the input. In Experiment 2, to test the generalizability of segmental invariance, we investigated the diminutive suffixes of Russian nominative masculine nouns and observed results highly similar to those for Dutch, despite the fact that Russian masculine diminutive endings have a syllable structure very different from Dutch diminutives. Furthermore, when we replicated a subpart of the Russian experiment with new foils, the same learning pattern emerged.

In this article, we have focused on the potential benefits from frequently occurring morphemes for solving the word segmentation problem. Certainly, learners are faced with a variety of other learning tasks when acquiring a language. Thus, the very same derivational and inflectional endings implicated in word segmentation also constitute information necessary for the acquisition of morpho-syntax. In other words, when learners encounter endings such as -ika, -iku, -ike, -iki, or -ikam, they will perceive these suffixes not just as word boundary cues, but also as cues to grammatical categories and inflectional paradigms. Saffran and Wilson (2003) have shown that for 1 -year-old infants, the output of word segmentation processes serves as input to successful learning of grammar. Extending this line of research to adult language learning is part of our ongoing research program.

In sum, in this study, we explored how invariance in the endings of diminutivized nouns provides a useful cue for word segmentation. Across two languages with highly distinctive diminutive derivations, final-syllable rhyme invariance served as a word segmentation cue in learners with no prior experience with the language. Noting and extracting invariance cues in natural speech seemed to occur rapidly, as was demonstrated by the fact that the presentation of only 60 repetitions of each target within the speech stream was sufficient to induce above-chance recognition, as compared with 300 repetitions in a similarly constructed experiment with artificially synthesized speech. Given the pervasiveness of diminutive forms in the child-directed speech registers of many of the world's languages, the effects of ending invariance cues would tend to be amplified in the input to young children.

\section{AUTHOR NOTE}

The experiments reported in this article were supported by British Academy Grant SG-35090. Please address correspondence to V. Kempe, Department of Psychology, University of Stirling, Stirling FK9 4LA, Scotland (e-mail: vk2@stir.ac.uk).

\section{REFERENCES}

Aslin, R. N., Woodward, J. Z., LaMendola, N. P., \& Bever, T. G. (1996). Models of word segmentation in fluent maternal speech to 
infants. In J. L. Morgan \& K. Demuth (Eds.), Signal to syntax: Bootstrapping from speech to grammar in early acquisition (pp. 117-134). Mahwah, NJ: Erlbaum.

BATCHELDER, E. O. (2002). Bootstrapping the lexicon: A computational model of infant speech segmentation. Cognition, 83, 167-206.

Bates, E., \& MACWhinney, B. (1987). Competition, variation, and language learning. In B. MacWhinney (Ed.), Mechanisms of language acquisition (pp. 157-193). Hillsdale, NJ: Erlbaum.

BooIJ, G. (1995). The phonology of Dutch. Oxford: Oxford University Press, Clarendon Press.

BRENT, M. R., \& CARTwRight, T. A. (1996). Distributional regularity and phonotactic constraints are useful for segmentation. Cognition, 61, 93-125.

BRENT, M. R., \& Siskind, J. M. (2001). The role of exposure to isolated words in early vocabulary development. Cognition, 81, B33-B44.

Brooks, P. J., \& ZizaK, O. (2002). Does preemption help children learn verb transitivity? Journal of Child Language, 29, 759-781.

Christiansen, M. H., Allen, J., \& Seidenberg, M. S. (1998). Learning to segment speech using multiple cues: A connectionist model. Language \& Cognitive Processes, 13, 221-268.

Curtin, S., Mintz, T. H., \& Christiansen, M. H. (2005). Stress changes the representational landscape: Evidence from word segmentation. Cognition, 96, 233-262.

CutLER, A. (1994). Segmentation problems, rhythmic solutions. Lingua, 92, 81-104.

Cutler, A., \& Norris, D. (1988). The role of strong syllables in segmentation for lexical access. Journal of Experimental Psychology: Human Perception \& Performance, 14, 113-121.

Echols, C. H., Crowhurst, M. J., \& Childers, J. B. (1997). The perception of rhythmic units in speech by infants and adults. Journal of Memory \& Language, 36, 202-225.

Elman, J. L., Bates, E. A., Johnson, M. H., Karmiloff-Smith, A., Parisi, D., \& Plunkett, K. (1996). Rethinking innateness: A connectionist perspective on development. Cambridge, MA: MIT Press.

Fernald, A., \& McRoberts, G. (1996). Prosodic bootstrapping: A critical analysis of the argument and the evidence. In J. L. Morgan $\&$ K. Demuth (Eds.), Signal to syntax: Bootstrapping from speech to grammar in early acquisition (pp. 365-388). Mahwah, NJ: Erlbaum.

GILLIS, S. (1997). The acquisition of diminutives in Dutch. In W. U. Dressler (Ed.), Studies in pre- and protomorphology (pp. 165-179). Vienna: Verlag der Österreichischen Akademie der Wissenschaften.

Golinkoff, R. M., \& ALIOTO, A. (1995). Infant-directed speech facilitates lexical learning in adults hearing Chinese: Implications for language acquisition. Journal of Child Language, 22, 703-726.

Gomez, R. L., \& GerKen, L. (1999). Artificial grammar learning by 1 -year-olds leads to specific and abstract knowledge. Cognition, 70, 109-135.

Gomez, R. L., \& Gerken, L. (2000). Infant artificial language learning and language acquisition. Trends in Cognitive Sciences, 4, 178-186.

Hoff, E. (2003). The specificity of environmental influence: Socioeconomic status affects early vocabulary development via maternal speech. Child Development, 74, 1368-1378.

Huttenlocher, J., Vasilyeva, M., Cymerman, E., \& Levine, S. (2002). Language input and child syntax. Cognitive Psychology, 45, 337-374.

JUSCZYK, P. W. (1997). The discovery of spoken language. Cambridge, MA: MIT Press.

JUSCZYK, P. W. (2002). How infants adapt speech-processing capacities to native-language structure. Current Directions in Psychological Science, 11, 15-18.

JUSCZYK, P. W., \& AsLIN, R. N. (1995). Infants' detection of sound patterns of words in fluent speech. Cognitive Psychology, 29, 1-23.
JusczyK, P. W., \& Hohne, E. A. (1997). Infants' memory for spoken words. Science, 277, 1984-1986.

JusczyK, P. W., Hohne, E. A., \& Bauman, A. (1999). Infant's sensitivity to allophonic cues for word segmentation. Perception \& Psychophysics, 61, 1465-1476.

JusczyK, P. W., Houston, D. M., \& Newsome, M. (1999). The beginnings of word segmentation in English-learning infants. Cognitive Psychology, 39, 159-207.

Kempe, V., Brooks, P. J., \& Gillis, S. (2005). Diminutives in childdirected speech supplement metric with distributional word segmentation cues. Psychonomic Bulletin \& Review, 12, 145-151.

Kempe, V., Brooks, P. J., Mironova, N., Pershukova, A., \& FedoROVA, O. (2007). Playing with word endings: Morphological variation in the learning of Russian noun inflections. British Journal of Developmental Psychology, 25, 55-77.

Kempe V., Brooks, P. J., \& Pirott, L. (2001). How can child-directed speech facilitate the acquisition of morphology? In M. Almgren, A. Barrena, M.-J. Ezeizabarrena, I. Idiazabal, \& B. MacWhinney (Eds.), Research on child language acquisition: Proceedings of the 8th Conference of the International Association for the Study of Child Language (pp. 1237-1247). Medford, MA: Cascadilla.

Kuhl, P. K., Andruski, J. E., Chistovich, I. A., Chistovich, L. A., Kozhevnikova, E. V., Ryskina, V. L., ET AL. (1997). Cross-language analysis of phonetic units in language addressed to infants. Science, 277, 684-686.

MatTys, S. L., \& JusczyK, P. W. (2001a). Do infants segment words or recurring contiguous patterns? Journal of Experimental Psychology: Human Perception \& Performance, 27, 644-655.

Mattys, S. L., \& JusczYK, P. W. (2001b). Phonotactic cues for segmentation of fluent speech by infants. Cognition, 78, 91-121.

Morgan, J. L. (1996). A rhythmic bias in preverbal speech segmentation. Journal of Memory \& Language, 35, 666-688.

Morgan, J. L., \& Demuth, K. (EDs.) (1996). Signal to syntax: Bootstrapping from speech to grammar in early acquisition. Mahwah, NJ: Erlbaum.

Morgan, J. L., \& Saffran, J. R. (1995). Emerging integration of sequential and suprasegmental information in preverbal speech segmentation. Child Development, 66, 911-936.

Redford, M. A., Davis, B. L., \& Miikkulainen, R. (2004). Phonetic variability and prosodic structure in mothers. Infant Behavior \& Development, 27, 477-498.

Saffran, J. R., Aslin, R. N., \& Newport, E. L. (1996). Statistical learning by 8-month-olds. Science, 274, 1926-1928.

Saffran J. R., Newport, E. L., Aslin, R. N., Tunick, R. A., \& BarRUECO, S. (1997). Incidental language learning: Listening (and learning) out of the corner of your ear. Psychological Science, 8, 101-105.

Saffran, J. R., \& Wilson, D. P. (2003). From syllables to syntax: Multilevel statistical learning by 12-month-old infants. Infancy, 4, 273-284.

SeidenberG, M. S., \& MacDonald, M. C. (1999). A probabilistic constraints approach to language acquisition and processing. Cognitive Science, 23, 569-588.

Taelman, H., \& Gillis, S. (2000). Gebruiken kinderen abstracte prosodische representaties? Een analyse van truncaties in het Maartencorpus. (Antwerp Papers in Linguistics, Vol. 99). Antwerp: Universitaire Instelling Antwerpen.

Tamis-LeMonda, C. S., \& Bornstein, M. H. (2002). Maternal responsiveness and early language acquisition. In R. Kail \& H. W. Reese (Eds.), Advances in child development and behavior (Vol. 29, pp. 89127). San Diego: Academic Press.

Weizman, Z. O., \& SnOw, C. E. (2001). Lexical input as related to children's vocabulary acquisition: Effects of sophisticated exposure and support for meaning. Developmental Psychology, 37, 265-279. 
APPENDIX A

Dutch Nonword Targets and Context Sentences Used in Experiments 1A and 1B

\begin{tabular}{|c|c|c|c|c|}
\hline \multirow{3}{*}{$\begin{array}{l}\text { Rhyme } \\
\text { Invariance }\end{array}$} & \multicolumn{4}{|c|}{ Onset Invariance } \\
\hline & \multicolumn{2}{|c|}{ Low } & \multicolumn{2}{|c|}{ High } \\
\hline & Targets & Foils & Targets & Foils \\
\hline \multirow[t]{11}{*}{ Low } & knoochtie & tieflijm & knoochjie & jieflijm \\
\hline & /kno $\chi \mathrm{ti} /$ & /tifleIm/ & /kno $\chi \mathrm{ji} /$ & /jifleım/ \\
\hline & steefkeu & keuvraul & steefjeu & jeuvraul \\
\hline & /stefkø/ & /køvraul/ & /stefjø/ & /jøvraul/ \\
\hline & schraamloo & loogluin & schraampjoo & pjoogluin \\
\hline & /s zamlo/ & /loylœyn/ & /s zampjo/ & /pjoylœyn/ \\
\hline & flijmsaa & saaknooch & flijmpjaa & pjaaknooch \\
\hline & /flcimsa/ & /sakno $\chi /$ & /fleimpja/ & /pjakno $\chi /$ \\
\hline & gluinfee & feeschraam & gluintjee & tjeeschraam \\
\hline & /ylœynfe/ & /fes $\chi \mathrm{ram} /$ & /ylœyntje/ & /tjes $\chi \mathrm{ram} /$ \\
\hline & $\begin{array}{l}\text { vraulpuu } \\
\text { /vraulpy/ }\end{array}$ & $\begin{array}{l}\text { puusteef } \\
\text { /pystef// }\end{array}$ & $\begin{array}{l}\text { vraultjuu } \\
\text { /vraultiv/ }\end{array}$ & $\begin{array}{l}\text { tjuusteef } \\
\text { /tivstef/ }\end{array}$ \\
\hline \multirow[t]{11}{*}{ High } & knoochte & teflijm & knoochje & jeflijm \\
\hline & /knoūtə/ & /toflcim/ & /kno & /jəflcim/ \\
\hline & steefke & kevraul & steefje & jevraul \\
\hline & /stefkə/ & /kevraul/ & /stefjə/ & /jevraul/ \\
\hline & schraamle & legluin & schraampje & pjegluin \\
\hline & (/s $\chi$ ramlə/ & /leylœyn/ & /s $\chi$ rampjə/ & /pjeylœyn/ \\
\hline & flijmse & seknooch & flijmpje & pjeknooch \\
\hline & /fleimsə/ & /sekno $\chi /$ & /fleimpjə/ & $/$ pjekno $\chi /$ \\
\hline & gluinfe & feschraam & gluintje & tjeschraam \\
\hline & /ylœynfə/ & /fes $\chi \mathrm{ram} /$ & /ylœyntjə/ & $/$ tjes $\chi \mathrm{ram} /$ \\
\hline & $\begin{array}{l}\text { vraulpe } \\
\text { /vraulpo/ }\end{array}$ & $\begin{array}{l}\text { pesteef } \\
\text { /pestef/ }\end{array}$ & $\begin{array}{l}\text { vraultje } \\
\text { /vraultjə/ }\end{array}$ & $\begin{array}{l}\text { tjesteef } \\
\text { /tjestef/ }\end{array}$ \\
\hline
\end{tabular}

\section{Context Sentences in Experiment 1A}

Toen tikte de grote jongen ___ op de arm en de schouder.

Ik sloeg haar omdat ze altijd aan mijn ___ zit.

Het meisje keek op haar___ voor de zekerheid.

Dan maak ik geen ___ meer in mijn berekeningen.

De rare ___ waarnaar jij mag verdwijnen is je bed.

Ze cirkelden om ___ heen op zoek naar voedsel.

\section{Context Sentences in Experiment 1B}

Drie preutse vrouwen in ___ uitrusting kleuren er rustig op los aan het antiek schrijftafel.

Naar mijn mening fnuiken de gore eindverslagen die ___ schrijft elk rechtvaardigheidsgevoel.

De dermatoloog zei dat___ een vorm van vreemdvoorwerp-reuscel-granulatieweefsel was.

De bijsluiter geeft géén ___ aanwijzing omtrent de overdraagbaarheid van de aandoening.

Michiel vraagt steevast om ___ te gebruiken als oplijningstoestel bij schijven.

Loop geen scheve schaats als de ___ de passie preekt aan knappe of felgekleurde doorgeefluiken. 
APPENDIX B

Russian Nonword Targets and Context Sentences Used in Experiment 2

\begin{tabular}{|c|c|c|c|c|}
\hline \multirow{3}{*}{$\begin{array}{l}\text { Rhyme } \\
\text { Invariance }\end{array}$} & \multicolumn{4}{|c|}{ Onset Invariance } \\
\hline & \multicolumn{2}{|c|}{ Low } & \multicolumn{2}{|c|}{ High } \\
\hline & Targets & Foils & Targets & Foils \\
\hline \multirow[t]{12}{*}{ Low } & zhagbul & bulfer & zhagchul & chulfer \\
\hline & /3agbul/ & /bulfer/ & /3agtj $\int j i k /$ & $/ \mathrm{tj} \int \mathrm{j}$ ulfer/ \\
\hline & ryumzov & zovzhag & ryumchov & chovzhag \\
\hline & $/ \mathrm{r}^{\mathrm{j}} \mathrm{umzov} /$ & /zovzag/ & $/ \mathrm{r}^{\mathrm{j}} \mathrm{umt} \int^{\mathrm{j}} \mathrm{j}$ ov/ & $/ \mathrm{t} \int^{\mathrm{j}} \mathrm{ov} \mathrm{ag} /$ \\
\hline & fermin & minryum & ferchin & chinryum \\
\hline & /fermin/ & /mivrium/ & $/$ fert $\int^{j} j_{i n} /$ & /t $\mathrm{j}{ }^{\mathrm{jin} i \mathrm{j}}{ }^{\mathrm{j} u m} /$ \\
\hline & sontub & tubvul & sonchub & chubvul \\
\hline & /sontub/ & /tubvul/ & $/$ sont $\mathrm{j}^{\mathrm{j}} \mathrm{j} \mathrm{ub} /$ & $/ \mathrm{t}^{\mathrm{j}}{ }^{\mathrm{j} u \mathrm{ubvul} /}$ \\
\hline & nivdap & dapson & nivchap & chapson \\
\hline & /nivdap/ & /dapson/ & $/$ nivt $^{\mathrm{j}} \int^{\mathrm{j}} \mathrm{ap} /$ & $/ \mathrm{t} \mathrm{j} \int \mathrm{j}$ apson/ \\
\hline & vulbor & borniv & vulchor & chorniv \\
\hline & /vulbor/ & /borniv/ & /vultijijor/ & $/ \mathrm{t} \mathrm{j} \int \mathrm{j}$ orniv/ \\
\hline \multirow[t]{12}{*}{ High } & zhagbik & bikfer & zhagchik & chikfer \\
\hline & /3agbik/ & /bikfer/ & /3agtj $\int \mathrm{jik} /$ & $/ \mathrm{t} \mathrm{j} \int \mathrm{jikfer} /$ \\
\hline & ryumzik & zikzhag & /ryumchik & chikzhag \\
\hline & $/ \mathrm{r}^{\mathrm{j}} \mathrm{umzik} /$ & /zikzag & $/ \mathrm{r}^{\mathrm{j}} \mathrm{umt} \mathrm{j}^{\mathrm{j}} \mathrm{jik} /$ & $/ \mathrm{t}^{\mathrm{j}} \mathrm{jik}^{\mathrm{jik}} \mathrm{ag} /$ \\
\hline & fermik & mikryum & ferchik & chikryum \\
\hline & /fermik/ & /mikrium/ & /fertj $\int \mathrm{jik} /$ & /tj $\int \mathrm{jikrjum} /$ \\
\hline & sontik & tikvul & sonchik & chikvul \\
\hline & /sontik/ & /tikvul/ & /sont $\mathrm{j} \mathrm{jik} /$ & $/ \mathrm{t} \mathrm{j} \int \mathrm{jikvul} /$ \\
\hline & nivdik & dikson & nivchik & chikson \\
\hline & /nivdik/ & /dikson/ & $/ \operatorname{nivt} \mathrm{j}^{\mathrm{j}} \mathrm{jik} /$ & $/ \mathrm{t} \mathrm{j} \int \mathrm{jikson} /$ \\
\hline & vulbik & bikniv & vulchik & chikniv \\
\hline & /vulbik/ & /bikniv/ & /vultj $\int \mathrm{jik} /$ & /tj $\int \mathrm{jikniv/}$ \\
\hline
\end{tabular}

Context Sentences in Experiment 2

Izvestno, chto vsegda nado brat' s soboj Predstav'te sebe, kak vygljadit takoj vozdukha.

Iz-pod etikh kupolov na lune. Poluchiv mashina vilol tjazhesti. Vnizu byl viden __ , s ulicami i plostchad'jami. 
APPENDIX C

Russian Foils Used in Experiment 3

\begin{tabular}{|c|c|c|c|c|c|c|c|}
\hline List 1 & List 2 & List 3 & List 4 & List 5 & List 6 & List 7 & List 8 \\
\hline biknal & ziknal & ziksul & zikprit & ziknem & bikprit & biksul & biknem \\
\hline /biknal/ & /3iknal/ & /3iksul/ & /3ikprit/ & $/ 3^{\mathrm{ikn}}{ }^{\mathrm{j}} \mathrm{em} /$ & /bikprit/ & /biksul/ & /biknjem/ \\
\hline bojryum & bojfer & chivfer & lovfer & kojfer & lovryum & chivryum & kojryum \\
\hline /boirjum/ & /boifer/ & $/ \mathrm{t} \mathrm{j} \int \mathrm{jivfer} /$ & /lovfer/ & /koifer/ & /lovrijum/ & $/ \mathrm{t}^{\mathrm{j}} \int \mathrm{jiivr}^{\mathrm{j}} \mathrm{Um} /$ & $/ \mathrm{ko}^{\mathrm{j}} \mathrm{r}^{\mathrm{j}} \mathrm{Om} /$ \\
\hline $\begin{array}{l}\text { miknem } \\
\text { /miknjem/ }\end{array}$ & $\begin{array}{l}\text { tiknem } \\
\text { /tiknjem/ }\end{array}$ & $\begin{array}{l}\text { tiknal } \\
\text { /tiknal/ }\end{array}$ & $\begin{array}{l}\text { tiksul } \\
\text { /tiksul// }\end{array}$ & $\begin{array}{l}\text { tikprit } \\
\text { /tikprit/ }\end{array}$ & $\begin{array}{l}\text { miksul } \\
\text { /miksul/ }\end{array}$ & $\begin{array}{l}\text { miknal } \\
\text { /miknal/ }\end{array}$ & $\begin{array}{l}\text { mikprit } \\
\text { /mikprit/ }\end{array}$ \\
\hline kojson & kojniv & bojniv & chivniv & lovniv & chivson & bojson & lovson \\
\hline /koison/ & /koIniv/ & /boiniv/ & $/ \mathrm{t} \mathrm{j} \int \mathrm{jivniv} /$ & /lovniv/ & $/ \mathrm{t}^{\mathrm{j}} \int \mathrm{ji}$ ivson/ & /boison/ & /lovson/ \\
\hline dikprit & bikprit & biknem & biknal & biksul & diknal & diknem & diksul \\
\hline /dikprit/ & /bikprit/ & /biknjem/ & /biknal/ & /biksul/ & /diknal/ & /diknjem/ & /diksul/ \\
\hline $\begin{array}{l}\text { lovvul } \\
\text { /lovvul/ }\end{array}$ & $\begin{array}{l}\text { lovzhag } \\
\text { /lovzag/ }\end{array}$ & $\begin{array}{l}\text { kojzhag } \\
\text { /koIzag/ }\end{array}$ & $\begin{array}{l}\text { bojzhag } \\
\text { /boizag/ }\end{array}$ & $\begin{array}{l}\text { chivzhag } \\
\text { /t }{ }^{\mathrm{j} j \mathrm{jiv}} \text { ag/ }\end{array}$ & $\begin{array}{l}\text { bojvul } \\
\text { /boIvul/ }\end{array}$ & $\begin{array}{l}\text { kojvul } \\
\text { /koIvul/ }\end{array}$ & $\begin{array}{l}\text { chivvul } \\
/ \mathrm{t}^{\mathrm{j}} \mathrm{j} \mathrm{j} \text { ivvul/ }\end{array}$ \\
\hline
\end{tabular}

Note-Pseudonoun targets were identical to the low-onset/high-rhyme-invariance condition in Experiment 2.

(Manuscript received March 21, 2005;

revision accepted for publication February 18, 2006.) 